\title{
ESTUDIOS DE BIOLOGÍA FLORAL, REPRODUCTIVA Y VISITANTES FLORALES EN EL "LOCHE" DE LAMBAYEQUE (Cucurbita moschata DUCHESNE)
}

\author{
STUDIES OF THE FLORAL, REPRODUCTIVE BIOLOGY AND FLORAL \\ VISITORS IN "LOCHE” OF LAMBAYEQUE (Cucurbita moschata DUCHESNE)
}

\author{
Isamar Bazo S. ${ }^{1 *}$, Rosa Espejo J. ${ }^{2}$, César Palomino A. ${ }^{3}$, Mercedes Flores P. ${ }^{4}$, Milagros Chang L. ${ }^{5}$, \\ César López B. ${ }^{6}$ y Roberto Mansilla S. ${ }^{7}$
}

\begin{abstract}
Resumen
En el Perú, Cucurbita moschata Duchesne tiene una variedad local llamada Loche, que se propaga por esquejes y de la que se conoce muy poco sobre su reproducción sexual. Por ello, el objetivo del presente trabajo fue evaluar la biología floral y reproductiva del Loche de Lambayeque. En esta especie las flores femeninas poseen mayor diámetro y longitud de corola que las masculinas, sin embargo, estas últimas presentan pedicelos y sépalos más largos. La floración masculina inició antes que la femenina con la aparición de los botones florales. En la antesis, las flores femeninas iniciaron este proceso antes que las masculinas. Asimismo, durante la producción de flores en promedio se observó 10 flores masculinas por cada flor femenina. En relación al grano de polen, éste tiene una viabilidad del $98 \%$ desde la antesis, la que decae hasta un $20 \%$ al día siguiente. El número promedio de granos de polen por flor osciló entre 25125 y 31833 y el diámetro presentó de 0.1 a $0.2 \mathrm{~mm}$. El estigma es receptivo durante tres días desde la antesis. La producción de néctar fue mayor en las flores femeninas que en las masculinas. El Loche presenta varios sistemas reproductivos: a nivel sexual, la geitonogamia y alogamia; y a nivel asexual, por medio de esquejes y apomixis facultativa, los cuales fueron determinados a partir de pruebas de polinización. Entre los polinizadores de C. moschata, el orden Hymenoptera tiene el mayor número de familias con afinidad por sus flores. Las familias Vespidae y Apidae son las de mayor regularidad en las visitas, siendo Drosophila sp. la de mayor duración en estancia.

Palabras clave: Cucurbita moschata, Loche, biología floral, biología reproductiva, polinizadores.
\end{abstract}

\begin{abstract}
In Peru, Cucurbita moschata Duchesne has a local variety called Loche, it is propagated by cuttings and little is known about its sexual reproduction. Therefore, the objective of the present work was to evaluate floral and reproductive biology in Loche from Lambayeque. The female flowers have a bigger diameter and corolla length than the male ones; however, the latter have longer pedicels and sepals. The male flowering begins before the female with the appearance of flower buds. Female flowers started anthesis process before male flowers. Likewise, during the production of flowers on average, 10 male flowers per female flower was observed. The pollen grain has a viability of $98 \%$ from anthesis and decreases to $20 \%$ in the next day. The number of average pollen grains per flower ranged between 25125 and 31833 and a diameter of 0.1 to $0.2 \mathrm{~mm}$. The stigma is receptive for three days from anthesis. Nectar production was higher in female flowers than in male ones. The Loche presents self-pollination, cross-pollination and open pollination by insects, where the order Hymenoptera has the highest number of families with affinity to flowers and families such as Vespidae and Apidae are the most regular in visits, being the longest in stay Drosophila sp. It also presents asexual reproduction through facultative apomixis.
\end{abstract}

Key words: Cucurbita moschata, Loche, floral biology, reproductive biology, pollinators.

\section{Introducción.}

La biología floral es un componente importante de la biología reproductiva de las plantas, debido a que investiga las relaciones mutuas entre las flores y su ambiente, biótico y abiótico, con respecto a la polinización (Mansilla et al., 2010). En sentido estricto, comprende los procesos de polinización y fecundación y su objetivo es explicar la función de los órganos florales, mediante el análisis de la morfología floral y el comportamiento de los agentes polinizadores (Mansilla et al., 2010). De acuerdo con Dafni (1992), el sistema reproductivo de las especies de plantas puede variar a lo largo de gradientes altitudinales y ecológicos. Por lo tanto, el conocimiento de la biología 
floral y del sistema reproductivo de las plantas con flores es fundamental para su manejo local. Conocer la biología floral también es de primordial importancia para implementar actividades de pre mejoramiento y fisiología de los cultivos (Corredor \& García, 2011).

Entre las especies de Cucurbita con valor alimenticio cultivadas en América se encuentra Cucurbita moschata Duchesne, que en el Perú tiene una variedad local en toda la costa norte llamada Loche, de la cual se conoce muy poco sobre los aspectos botánicos (Delgado et al., 2014), y solo se sabe que se propaga asexualmente por esquejes (Ugás, 2014). Adicionalmente la literatura científica sobre la biología de la especie es escasa, con excepción del importante rol que tiene en la gastronomía norteña del Perú (Delgado et al., 2014).

C. moschata tiene el valor nutricional más alto entre las especies cultivadas de Cucurbita (López et al., 2014) y también el mayor precio en el mercado nacional, llegando a costar de 5-10 veces más que los otros zapallos (Bustamante \& Ugás, 2006; Ugás, 2014). El hecho de tener un alto potencial comercial y escasa información sobre su cultivo, y sobre todo de su biología reproductiva, fue lo que nos motivó a realizar el estudio de la morfología floral, la fenología, el sistema reproductivo e indagar sobre los polinizadores más usuales del Loche.

\section{Materiales y métodos.}

\section{Material Vegetal.}

El material vegetal estuvo constituido por 40 esquejes extraídos de un campo de cultivo tradicional de Loche localizado en el distrito de Pomac III en Chiclayo-Lambayeque. Se sembraron también 40 plantas provenientes de semillas de $C$. moschata en un sistema de cultivo sin suelo.

Para realizar el cultivo ex situ de $C$. moschata a partir de semillas se seleccionaron 20 frutos, de los cuales, por cada uno de los frutos, se utilizaron dos semillas, haciendo un total de 40 plantas procedentes de semilla sexual, de acuerdo a una longitud entre $20 \mathrm{y}$ $30 \mathrm{~cm}$ y un diámetro entre 10 y $20 \mathrm{~cm}$. Las semillas extraídas se pusieron a secar por no menos de cinco días a temperatura ambiente antes del proceso de imbibición, el cual consistió en sumergir las semillas en agua por 24 horas el día previo a la siembra. La germinación se llevó a cabo en un vaso de poliestireno expandido (Tecnopor) utilizando como sustrato arena fina de cantera (lavada y desinfectada con hipoclorito de sodio al 1.5\%). El riego del almácigo se realizó diariamente con agua hasta diez días después de la emergencia de los cotiledones; a partir de este día se remplazó el agua por una solución nutritiva (187 ppm de N, 45 ppm de P, 252 ppm de K, 150 ppm de Ca, 45 ppm de $\mathrm{Mg}, 60$ ppm de S, 2 ppm de Fe, 0.6 ppm de B, 0.5 ppm de $\mathrm{Mn}, 0.16 \mathrm{ppm}$ de $\mathrm{Zn}, 0.15$ ppm de $\mathrm{Cu}, 0.01$ ppm de Mo, pH 6.5-7.0 y CE 2.3-2.4 mS). Al cabo de un mes las plántulas fueron trasplantadas a sacos de plástico (de $80 \times 50 \mathrm{~cm}$ ) rellenos con el mismo sustrato utilizado para el proceso de germinación.

Los esquejes fueron tratados con el enraizador comercial RootHort ${ }^{\circledR}$ para promover el crecimiento y establecimiento de las plantas en contenedores de madera de $1.5 \times 1 \times 0.25 \mathrm{~m}$, forrados con plástico negro agrícola de 6 micras y con drenaje para evitar el estancamiento de la solución nutritiva. Cada contenedor fue llenado con 300 litros (1) de sustrato conformado por arena gruesa de cantera tamizada, lavada con agua potable y desinfectada con una solución de lejía comercial al $10 \%$. El cultivo sin suelo de $C$. moschata fue establecido en el Centro de Investigación de Hidroponía y Nutrición Mineral del Departamento de Biología y en un tinglado cubierto con malla antiáfidos, ambas instalaciones localizadas en el campus de la Universidad Nacional Agraria La Molina.

Biología Floral.

Morfología.

Para describir la morfología floral se utilizaron las mediciones de 30 plantas procedentes de semillas y de 30 plantas procedentes de esquejes, y se utilizaron como una sola muestra, porque al hacer comparaciones de Mann-Whitney entre estas dos supuestas muestras, estadísticamente no mostraron diferencias significativas. El cultivo de estas plantas se llevó a cabo entre los meses de marzo a diciembre del 2015 y de marzo a diciembre del 2016.

La estructura de las flores, su posición en la inflorescencia y la morfología de las flores masculinas y femeninas, se evaluaron el día de la antesis siguiendo la metodología de Ashworth \& Galetto (1999). Las medidas morfométricas se tomaron en milímetros ( $\mathrm{mm})$ y fueron las siguientes: longitud de la corola, diámetro de la corola, longitud del tubo corolino, diámetro del cáliz, longitud de sépalos, longitud del sinandro, diámetro del sinandro, longitud del estigma, longitud del estilo, ancho del estilo, ancho del ovario y pedúnculo. Estas mediciones se realizaron en tres flores masculinas y dos femeninas por planta. Los nombres a usar para la descripción de las partes florales fueron tomados de Lira \& Rodríguez (1999). Se utilizó un Vernier electrónico TRUPER® modelo CALDI-6MP para realizar las mediciones.

Desarrollo fenológico floral.

Para el establecimiento de las fenofases dentro del desarrollo fenológico floral de $C$. moschata, se realizó el monitoreo desde la germinación hasta la senescencia de 15 plantas en total (cinco de ellas sembradas en el mes de mayo, otras cinco en el mes de julio del 2015 y cinco plantas más se sembraron en marzo del 2016).

La identificación de las fenofases florales se elaboró en base a los criterios de identificación para Cucumis sativus, Cucumis melo, Cucurbita pepo, y Citrullus vulgaris, establecidos por Feller (1995) citado por Meier (2001). En este estudio se consideró como inicio de la fenofase de floración la aparición de los botones 
florales y los datos fueron registrados cuantitativamente considerando el número de plantas por cada estadío fenológico floral. Al respecto, se indica que se considera el inicio de una fenofase floral en la muestra cuando aproximadamente el $10 \%$ de los individuos en la muestra se encuentran en dicha fase, que el evento está en su punto máximo cuando más del $50 \%$ de las plantas en evaluación se encuentran en la misma fase, que está finalizando cuando menos del $10 \%$ de los individuos permanecen en dicha fase y que ha culminado cuando ningún individuo se encuentra en la fase.

Los botones florales fueron observados desde su aparición hasta la antesis con la finalidad de establecer: la hora de apertura y cierre floral, para lo cual se utilizaron 90 flores en total (entre masculinas y femeninas) evaluadas en tres días no consecutivos, durante el periodo de floración en los años 2015 y 2016. La producción semanal de flores masculinas y femeninas también se evaluó siguiendo el mismo esquema del establecimiento de fenofases florales, y usando como datos el número total de flores en cinco ramas laterales por planta. También se evaluó la proporción del número de flores femeninas en relación al número de flores masculinas, hallando el número promedio de flores en tres ramas laterales de una misma planta; se utilizaron diez plantas provenientes de esquejes para el año 2015 y diez plantas provenientes de semillas para el año 2016 y por tres días no consecutivos durante el periodo de floración masculina y femenina.

Producción, viabilidad y diámetro del grano de polen de C. moschata.

La viabilidad del polen fue evaluada en 10 plantas (una flor por planta) en el día de antesis durante tres días no consecutivos, dentro del periodo de floración masculina en el año 2016. Las evaluaciones se realizaron sobre la misma flor, la cual fue aislada y se extrajo el polen con intervalos de una hora y media a partir de la apertura floral hasta llegar a la marchitez de la flor y 24 horas después.

La metodología seguida para cuantificar la viabilidad de los granos de polen fue por el método de tinción con una solución de aceto-orceína al 2\% (Lyra et al., 2011). Después de recolectar todo el polen de una flor, éste fue colocado en un portaobjetos y teñido con la solución de aceto-orceína, luego se cubrió con una lámina cubreobjetos y fue observado al microscopio compuesto Zeiss Estándar 25.

Para evaluar la producción de polen se utilizó el método descrito por Sánchez (2015) con algunas modificaciones. El muestreo se realizó durante tres días no consecutivos durante el periodo de floración masculina en tres flores por planta y en 20 plantas diferentes por día de evaluación. Para ello, las flores seleccionadas fueron observadas días previos a la antesis y se les cubrió con papel Kraft para evitar que los polinizadores pudieran extraer el polen. El día de la antesis, se colectó todo el polen de una flor en un vial y en este envase se le adicionó un volumen de 5 mililitros de una solución de Tween al 1\% y con la ayuda de un vortex se homogenizó toda la solución. Se utilizaron 20 microlitros (ul) (como alícuota) para colocarlos en un portaobjetos (esta placa incluyó una cuadrícula marcada de $10 \times 10 \mathrm{~mm}$ ). Por flor evaluada se tomaron tres alícuotas y en cada alícuota se observaron al microscopio 10 campos visuales para el conteo del polen.

El diámetro de los granos de polen fue registrado en milímetros en tres flores por planta, en veinte plantas diferentes por día de evaluación y en tres días no consecutivos durante el periodo de floración masculina en los años 2015 y 2016. Se realizaron las mediciones del diámetro de tres granos de polen de una misma flor y se halló el diámetro promedio de todas las flores evaluadas por planta.

El polen extraído de una flor fue colocado directamente en un portaobjetos y observado en un microscopio Olympus LX41 con la ayuda del programa Q-capture Pro 7th, anexado a la cámara filmadora del microscopio que permitió captar la imagen del polen y hacer una medición el diámetro del polen.

\section{Receptividad estigmática.}

En la madurez floral, cuando los estigmas están listos para la polinización, estos se caracterizan por tener gran actividad peroxidasa (McInnis et al., 2006); por ello, con la finalidad de determinar la receptividad del estigma en el día de antesis y los días posteriores a éste, se realizó la prueba con peróxido de hidrogeno. Para esto se propusieron cuatro niveles de burbujeo, los cuales fueron utilizados como criterio de puntuación para convertir esta característica en una variable cuantitativa y así hallar la receptividad promedio por día evaluado.

La receptividad del estigma fue evaluada en 15 plantas (procedentes del cultivo de semillas y esquejes) evaluándose una flor por planta durante siete días consecutivos desde la antesis, entre los meses de septiembre y octubre del $2015 \mathrm{y}$, entre octubre noviembre de 2016. Para ello, se utilizó una solución de peróxido de hidrogeno de 10 volúmenes como indicador de actividad enzimática de la superficie del estigma (Mansilla et al., 2010).

La actividad enzimática fue reconocida como positiva al observar la presencia del burbujeo hasta en 4 diferentes niveles establecidos al adicionar $10 \mathrm{ul} \mathrm{de}$ peróxido de hidrógeno en la superficie del estigma con ayuda de una micropipeta.

\section{Producción de néctar.}

La producción de néctar en unidades volumétricas fue evaluada en las flores femeninas y masculinas el día de antesis, en los años 2015 y 2016. El muestreo se realizó en una flor femenina y en tres masculinas por planta, evaluando 10 plantas por día y en 3 días no consecutivos considerando la hora de apertura y cierre floral (6:00 a.m. y 12:00 p.m. aproximadamente) 
durante el periodo de floración. Con una micro pipeta se colectó todo el volumen del néctar contenido en los nectarios de la flor (Nepi et al., 1996).

Biología reproductiva.

Para la evaluación del tipo de sistema reproductivo se seleccionaron cuatro grupos de botones florales femeninos y masculinos en la etapa previa a la antesis. Cada grupo de evaluación estuvo compuesto de 10 plantas de C. moschata, 5 de ellas provenientes de semillas y 5 de ellas provenientes de esquejes. Los grupos fueron codificados del I-IV. Esta codificación hace referencia a los tratamientos de polinización que se pusieron en experimentación para identificar el (los) sistema(s) reproductivo(s) presente(s) (Shivanna \& Tandon, 2014); así, tenemos el grupo I: autogamia geitonogamia (polinización con polen de una misma planta), el grupo II: apomixis (sin polinización), el grupo III: alogamia - xenogamia (polinización con polen de otra planta) y el grupo IV: polinizaciones abiertas. El día previo a la antesis de los botones florales de los grupos I-III, estos fueron cubiertos con una bolsa de papel Kraft, y en el día de la antesis se procedió a las polinizaciones en cada grupo de evaluación.

Después de que las flores femeninas comenzaron la senescencia, o el estigma perdió receptividad, se retiraron las bolsas de los grupos I-III. En los grupos en los que se formaron frutos, al llegar estos a la etapa de maduración, fueron colectados con la finalidad de determinar el porcentaje de frutos cuajados y el número promedio de semillas por fruto por cada tipo de polinización. La interpretación de los resultados se realizó en base a la tabla propuesta por Shivanna \& Tandon (2014) para la producción esperada de frutos y semillas a partir de varios tratamientos de polinización para identificar los sistemas de reproducción y apareamiento en diversas especies. Se pudo determinar el sistema de reproducción de acuerdo a la relación polen/ovulo propuesta por Cruden (1977), donde el número de óvulos fue obtenido de manera indirecta realizando el conteo total de semillas por fruto (Sánchez, 2015). No se realizó el conteo directo de óvulos porque se produjeron abortos tempranos de flores femeninas después de ser polinizadas (posiblemente por las condiciones ambientales especiales que se produjeron en el año 2016 a consecuencia del Fenómeno del Niño Costero).

Polinización y visitantes florales.

Para la observación de polinizadores se visitaron tres campos de cultivo tradicional de Loche localizados en el caserío de Pomac III del distrito de Pítipo de la provincia de Lambayeque. Los muestreos y observaciones se realizaron durante el periodo de floración del cultivo, entre las 6 a.m. y las 2 p.m. Se realizó un registro de los polinizadores más usuales en el ambiente en el que se desarrolla normalmente el cultivo, teniendo para este propósito el registro fotográfico y/o fílmico y, en algunos casos, la captura directa de algunos de ellos con la ayuda de bolsas de papel Kraft para su posterior adormecimiento en frascos de vidrio que contenían $3 \mathrm{~g}$ de paradiclorobenceno. Los polinizadores y visitantes florales colectados fueron preservados en alcohol al $70 \%$ hasta su identificación, la cual se realizó de acuerdo al procedimiento de Rafael et al. (2012). Parámetros meteorológicos.

Los parámetros meteorológicos de temperatura, humedad relativa y precipitación promedio semanal durante el periodo de cultivo de $C$. moschata, fueron proporcionados por el observatorio Alexander Von Humboldt.

Análisis de datos.

En todos los casos donde se evaluaron datos cuantitativos se hallaron medidas de tendencia central como la media, mediana, desviación estándar y coeficiente de variabilidad. Para el análisis inferencial y de correlaciones se realizaron comparaciones de pruebas paramétricas y no paramétricas bajo un diseño completamente al azar, a un nivel de significancia de $0.05(\alpha=0.05)$. El análisis se realizó utilizando el paquete estadístico Minitab ®17.

\section{Resultados y discusión.}

\section{Biología floral.}

\section{Morfología.}

La especie Cucurbita moschata es de crecimiento anual, rastrera, trepadora con vástagos y zarcillos presentes en las axilas de las hojas. El tallo principal, y demás vástagos, son de consistencia dura y fistulosas, y están cubiertos de una pubescencia compuesta de tricomas urticantes, tal como lo registra Wessel-Beaver et al. (2004). El crecimiento de las ramas es muy vigoroso y tiene una tasa de crecimiento muy elevada que difícilmente puede ser igualada por otras especies de plantas herbáceas y anuales (Whitaker \& Davis, 1962).

Con respecto a la morfología floral, $C$. moschata es una planta monoica con flores unisexuales solitarias y actinomorfas, de perianto pentámero, tal como lo describen Hayward (1953) y Agbagwa et al. (2007). En común, ambas flores (Figura 1) tienen un cáliz gamosépalo compuesto de 5 sépalos lineales de color verde con tricomas urticantes; una corola gamopétala, acampanada y 5-lobada de coloración amarillo intenso en las flores femeninas y que puede llegar a tomar tonalidades un tanto más intensas que las masculinas. En ambos tipos de flores, el nectario se encuentra sobre la base del hipanto tal como lo describe Crase (2011) en la caracterización de las especies del género Cucurbita.

Todos los caracteres florales mencionados presentaron un coeficiente de variabilidad alto, es decir, mostraron gran variación en su tamaño (Tabla 1). Esto se puede deber a factores genéticos y ambientales, como fue mencionado por Maynard (2007). 


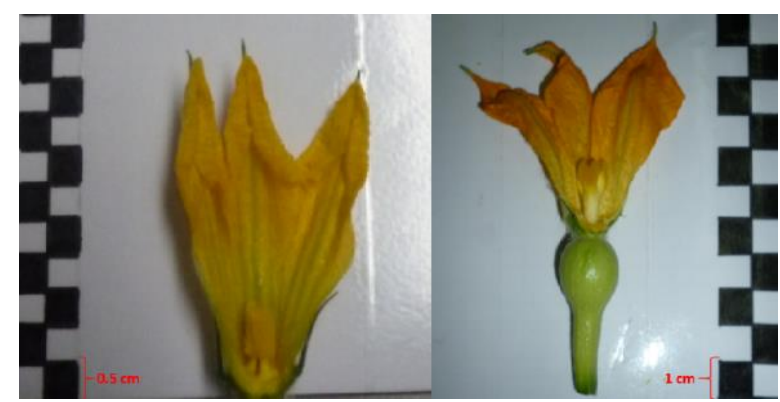

Figura 1. Flor femenina (derecha) y flor masculina (izquierda) de C. moschata.

De las mediciones realizadas, todos los caracteres florales evaluados en ambos tipos de flores, son diferentes en longitud y diámetro tanto en las flores masculinas como en las femeninas, tal como se puede observar en la Tabla 2.

Hayward (1953) menciona que las flores pistiladas son más grandes que las estaminadas. En este estudio aquellas características que corroboraron lo argumentado por este autor son el diámetro y la longitud de corola, cuyas medianas fueron mayores en las flores pistiladas que en las estaminadas. Por el contrario, en el caso de la longitud del pedicelo y de los sépalos, las flores estaminadas presentan un valor mayor de la mediana que las flores pistiladas. Estas diferencias también han sido registradas por Ashworth \& Galetto (2001) en Cucurbita maxima.

Las flores estaminadas o masculinas se hallan en los nudos basales y centrales, mientras que las flores pistiladas o femeninas se ubican en los nudos centrales y con mayor abundancia en las terminaciones de las guías vegetativas. Esta misma disposición fue observada por Ashworth \& Galetto (2001) y Hayward (1953) en C. maxima; este último mencionó también que este patrón de distribución es propio de las especies rastreras dentro del género Cucurbita.

\section{Desarrollo fenológico.}

\section{Fases fenológicas florales en $\boldsymbol{C}$. moschata}

En el año 2015, en las tres repeticiones que se trabajaron con la finalidad de establecer las fenofases y estadios fenológicos, la aparición de los botones masculinos se dio entre la semana 10 y 11 del cultivo,
Tabla 2. Comparación de medianas (en mm) por medio de la prueba de Mann-Whitney de los caracteres morfológicos comunes entre las flores masculinas y femeninas.

\begin{tabular}{|c|c|c|c|c|}
\hline 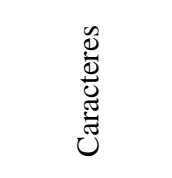 & 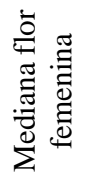 & 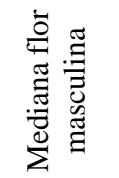 & 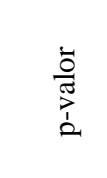 & 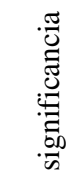 \\
\hline $\begin{array}{l}\text { Longitud de } \\
\text { pedicelo }\end{array}$ & 56.47 & 127.69 & 0.000 & $* *$ \\
\hline $\begin{array}{l}\text { Diámetro de } \\
\text { corola }\end{array}$ & 70.205 & 58.72 & 0.000 & $* *$ \\
\hline $\begin{array}{l}\text { Longitud de } \\
\text { corola }\end{array}$ & 65.35 & 61.25 & 0.0006 & $* *$ \\
\hline $\begin{array}{l}\text { Longitud de } \\
\text { sépalos }\end{array}$ & 14.66 & 19.235 & 0.000 & $* *$ \\
\hline
\end{tabular}

y 2 semanas más tarde ocurrió la aparición de los botones femeninos.

En la fenofase de floración (Tabla 3), de la repetición experimental sembrada en mayo, los botones florales masculinos tuvieron una duración de 13 semanas, y en el caso de los femeninos de 9 semanas; para la sembrada en julio, los botones masculinos tuvieron una duración de 11 semanas y los femeninos de 6 semanas. Para la repetición sembrada en marzo del 2016, los botones masculinos tuvieron una duración de 24 semanas y los femeninos de 5 semanas.

Agbagwa et al. (2007) reportaron resultados similares para $C$. moschata; la floración masculina ocurrió 8 semanas después de la germinación y la floración femenina 3 semanas después. Con respecto a la duración de la fenofase de floración, ésta también fue variable en los tres experimentos realizados; la floración femenina duró de 5-9 semanas y la masculina de 13-24 semanas.

A partir de estos resultados se puede afirmar que en C. moschata la floración masculina inicia primero que la femenina, siendo este patrón de floración propio de las cucurbitáceas que son monoicas (Whitaker \& Davis, 1962; Nepi et al., 1996; Maynard, 2007; INTA, 2013).

\section{Antesis: horas de apertura y cierre floral}

En la antesis, las horas de apertura y cierre floral se evaluaron, en el 2015, los días 5 y 21 de septiembre y

Tabla 1. Morfometría de las flores masculinas y femeninas del Loche.

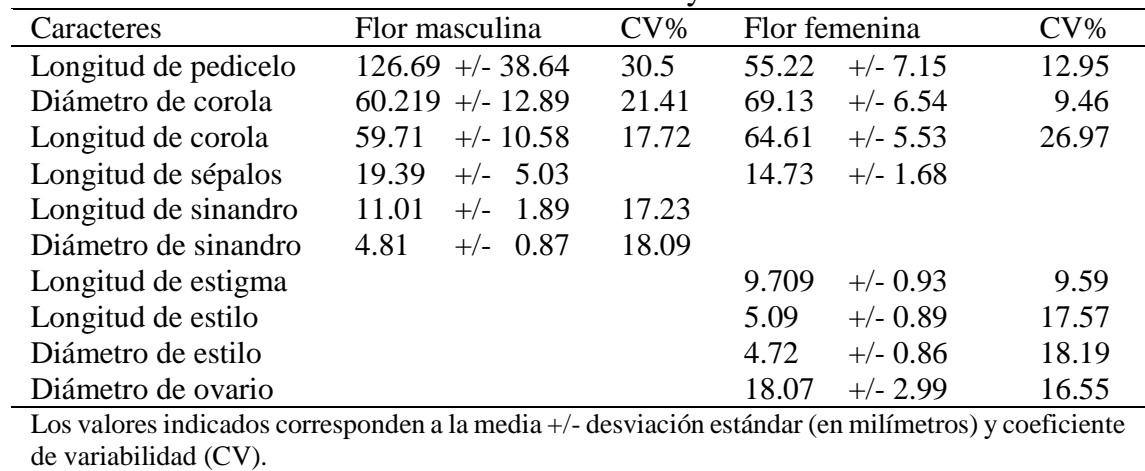


Tabla 3. Descripción de las fases fenológicas durante el desarrollo de flores masculinas y femeninas del Loche.

\begin{tabular}{lll}
\hline Fenofase & Estadío fenológico & Descripción \\
\hline Emergencia de la flor & Incipiente botón floral & $\begin{array}{l}4-8 \mathrm{~mm} \mathrm{de} \mathrm{longitud} \mathrm{con} \mathrm{sépalos} \mathrm{definidos} \mathrm{y} \\
\text { pubescentes. } \\
\text { Floración }\end{array}$ \\
Botones cerrados y la corola tiene una coloración verde \\
$\begin{array}{l}\text { Floración } \\
\text { Floración }\end{array}$ & $\begin{array}{l}\text { Apertura floral: inicio de antesis } \\
\text { Antesis completa }\end{array}$ & $\begin{array}{l}\text { Corola amarillo intenso. } \\
\text { Flores abiertas y los órganos sexuales totalmente } \\
\text { expuestos. }\end{array}$ \\
Floración & Marchitez & $\begin{array}{l}\text { La corola pierde turgencia y toma una coloración marrón } \\
\text { claro para luego desprenderse del pedicelo y caer. }\end{array}$ \\
\hline a.En los botones femeninos además se nota el ovario como una leve protuberancia.
\end{tabular}

el 13 de octubre, y durante el 2016, el 15 de septiembre y los días 8 y 9 de octubre.

En el 2015, el 50\% de los botones florales femeninos iniciaron la apertura floral a las 4:20 a.m. y en el 2016 a las 4:30 a.m. En las flores masculinas en el 2015 , el $50 \%$ de los botones florales masculinos iniciaron la apertura floral a las 5:30 a.m. y en el 2016 a las 5:20 a.m. En los dos años de evaluación, a las 6:00 a.m. todos los botones florales habían iniciado la apertura floral (Figura 2). Alrededor de las 11:00 a.m., ambos tipos de flores se encontraban en el estadio fenológico de floración completa, donde la corola se encontraba completamente abierta.

Las evaluaciones de cierre floral se realizaron el mismo día que las de apertura. En el año 2015, el 50\% de las flores femeninas ya se encontraban cerradas a la 1:00 p.m. y en el año 2016 media hora antes, es decir alrededor de las 12:30 p.m. (Figura 3). En las flores masculinas, la hora de cierre floral para ambos años de evaluación fue a la 1:30 p.m; en esta hora el 50\% de todas las flores se encontraba totalmente cerradas. A las 2:30 p.m., el $100 \%$ de todas las flores evaluadas, se encontraba en el estadio fenológico de marchitez.

Las evaluaciones realizadas demuestran que la duración desde el estado fenológico de floración hasta la marchitez es de aproximadamente 10 horas para ambos tipos de flores (Figura 4). Las flores masculinas tienen un periodo más corto de apertura floral a diferencia de las femeninas, las cuales presentan un tiempo más prolongado (casi el doble que las masculinas) para llegar a la apertura de todas las flores (Figura 4). En cuanto al tiempo, desde la apertura hasta alcanzar el $100 \%$ de expansión del diámetro de la corola y el cierre floral, no se observaron diferencias significativas en ambos tipos de flores.

Resultados similares a los presentados en este estudio para los sucesos de antesis, apertura y cierre floral han sido obtenidos por Agbagwa et al. (2007) y Nicodemo et al. (2007); estos autores para C. moschata y $C$. pepo respectivamente reportaron que la hora de apertura para ambos tipos de flores fue entre las 3:30 y 4:00 a.m., y una duración de la antesis de 6 horas aproximadamente. Esto se puede deber a que eventos climáticos como lluvias, o ausencia de sol, no interfieren con el inicio de la apertura floral (Ashworth \& Galetto, 1999). Por el contrario, con respecto a la hora de cierre floral, no se han reportado resultados similares a los presentados en este estudio dentro de la familia de las cucurbitáceas; una de las razones puede ser debido a las diferentes temperaturas y humedades

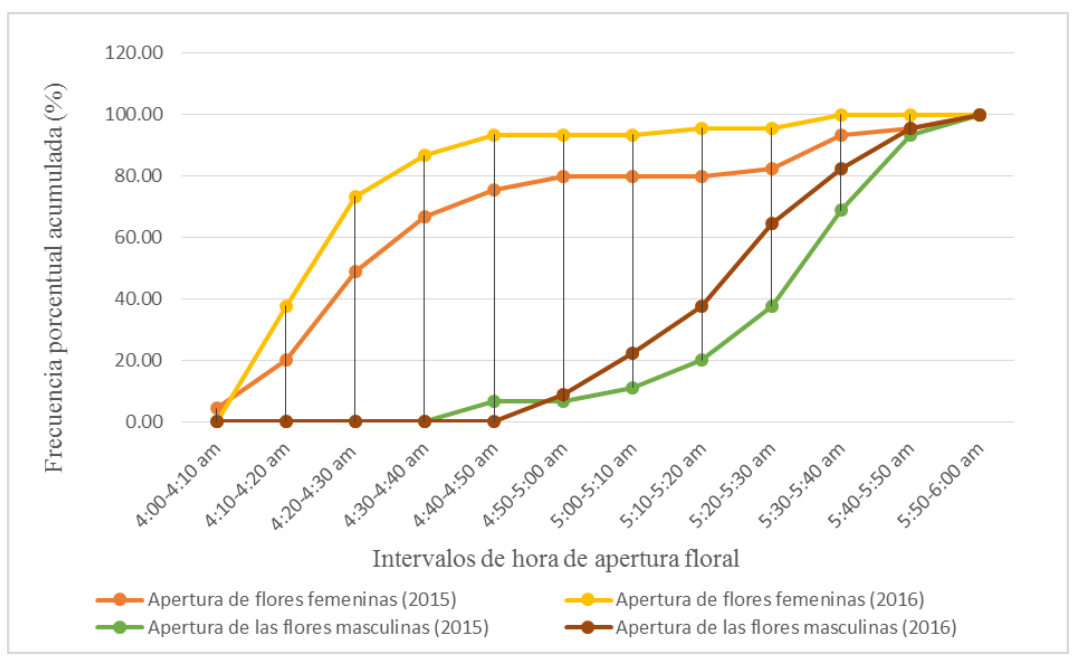

Figura 2. Apertura floral de los botones masculinos y femeninos evaluados entre los años 2015 y 2016 (n=90 flores). 


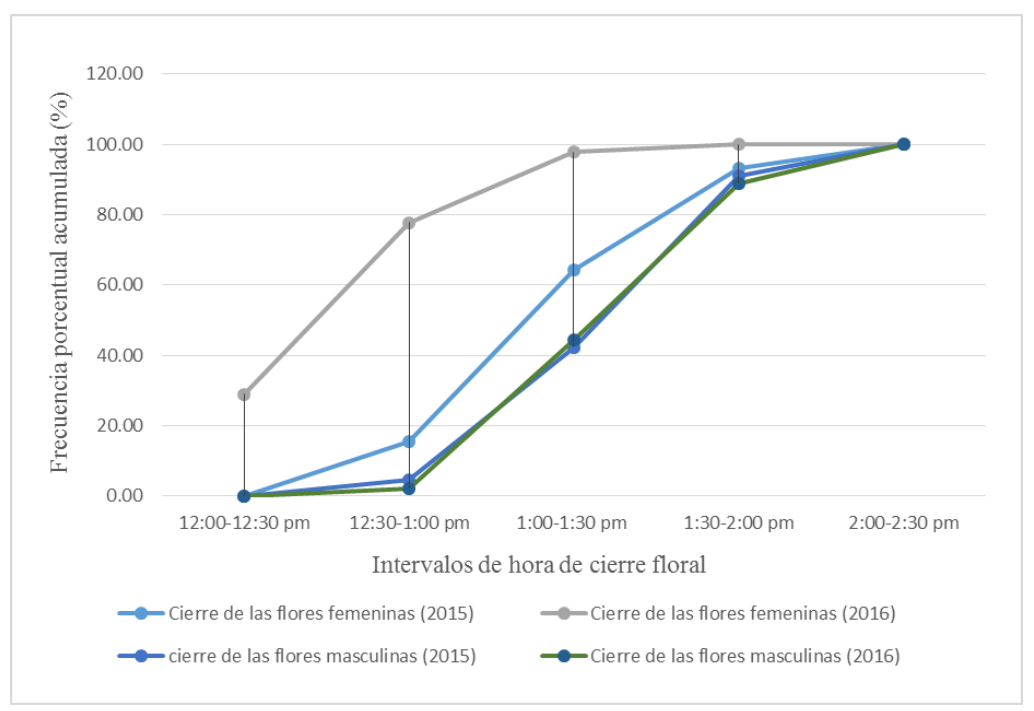

Figura 3. Cierre floral masculino y femenino evaluado entre los años 2015 y 2016 ( $n=90$ flores).

relativas, ya que estos parámetros meteorológicos afectan la integridad de la corola provocando un cierre floral en un tiempo diferente a otros estudios de fenología en cucurbitáceas.

\section{Producción de flores}

De las tres repeticiones experimentales realizadas en el 2015 y 2016 (Figura 5), las dos primeras llevadas a cabo tienen un patrón similar en cuanto al inicio, término y número de semanas de producción de flores (Figura 5). En las flores masculinas, la producción inició en la semana diez y terminó en la veintisiete de cultivo, y en las femeninas ocurrió entre las semanas trece y veinticuatro. También se observó que la mayor producción de flores masculinas en ambas repeticiones se da posteriormente a un periodo donde se presentaron las temperaturas más altas, y por el contrario, la mayor producción de flores femeninas se dio luego de un periodo donde se presentaron las temperaturas más bajas. Adicionalmente, se observó que la mayor producción de ambos tipos florales ocurrió entre las semanas trece y veinte del cultivo.
En la tercera repetición, la producción de flores masculinas ocurrió entre la semana diez y la treintainueve del cultivo, que comparada con las dos repeticiones experimentales anteriores mantiene el mismo patrón de producción. En el caso de las flores femeninas, la producción se dio entre la veintisiete y treintaisiete semanas del cultivo, siendo este patrón de producción diferente al observado en las dos primeras repeticiones experimentales en cuanto al inicio y término de este periodo de producción. Adicionalmente, se observó que la mayor producción de ambos tipos de flores se dio entre las semanas veintinueve y treintaicinco de cultivo.

De acuerdo con lo descrito por Maynard (2007) para el género Cucurbita, las temperaturas frías promueven el desarrollo de flores femeninas y las temperaturas altas promueven el desarrollo de flores masculinas y retrasan el de las femeninas. Esta información ha sido corroborada con los resultados obtenidos en las tres repeticiones experimentales. Por otra parte, en las tres repeticiones se observó que el traslape de producción de las flores masculinas y

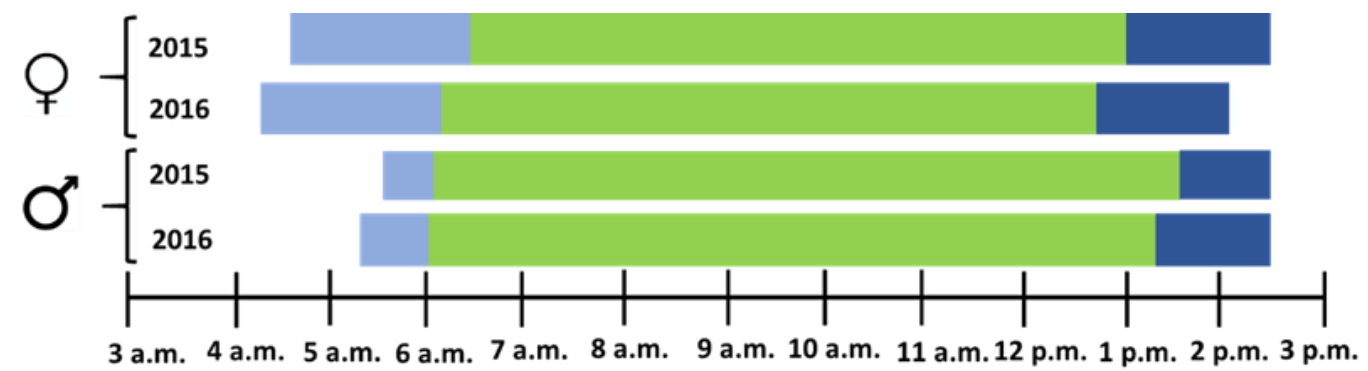

Barras en celeste indican apertura floral, barras en verde indican antesis floral y barras en azul indican el cierre floral.

Figura 4. Duración de la apertura, antesis, y cierre floral en flores de C. moschata evaluadas en el 2015 y 2016. 


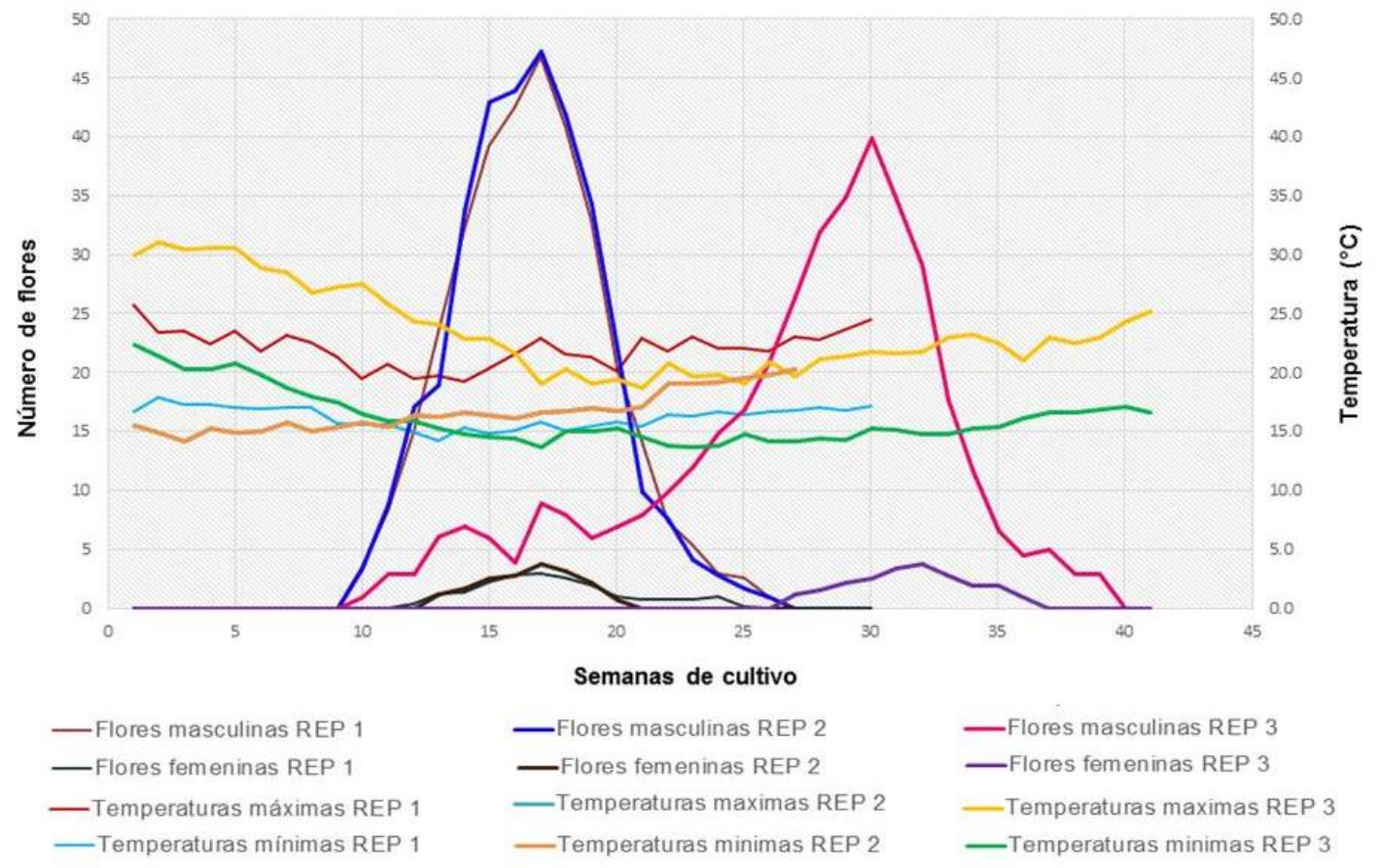

Figura 5. Producción de flores en C. moschata.

femeninas se dio en los mismos rangos de temperaturas.

Proporción del número de flores femeninas y masculinas

De la evaluación que se realizó en el año 2015 (Tabla 4), no se encontraron diferencias significativas en el número promedio de flores femeninas por rama en los tres días evaluados siendo, la mediana en las tres muestras una flor.

Para las flores masculinas, sí existieron diferencias significativas entre los días evaluados $(\mathrm{p}=0.001)$, en la prueba de comparación, un grupo de K-W estuvo formado por los días de evaluación 2 y 3, donde las medianas son 9.5 y 9 flores y separó como otro grupo al día de evaluación 1.

En el 2016 (Tabla 4); no existen diferencias estadísticas entre la cantidad de flores femeninas por

Tabla 4. Análisis comparativo de la proporción de flores masculinas y femeninas evaluadas en el año 2015 y 2016.

Año de evaluación $2015 \quad 2016$

Tipo de flor

\begin{tabular}{|c|c|c|c|c|}
\hline 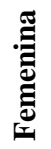 & 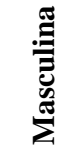 & 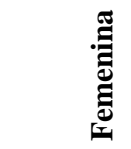 & & 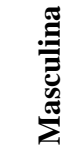 \\
\hline & $10^{\mathrm{b}}$ & 05-sep & $1^{\mathrm{a}}$ & $10^{\mathrm{a}}$ \\
\hline
\end{tabular}

\begin{tabular}{|c|c|c|c|c|c|c|}
\hline & 15-oct/Día 1 & $1^{\mathrm{a}}$ & $10^{\mathrm{b}}$ & 05-sep & $1^{\mathrm{a}}$ & $10^{\mathrm{a}}$ \\
\hline & 03-sep/ Día 2 & $1^{\mathrm{a}}$ & $9.5^{\mathrm{a}}$ & 28-sep & $1^{\mathrm{a}}$ & $10^{\mathrm{a}}$ \\
\hline 式 & 26-sep/ Día 3 & $1^{\mathrm{a}}$ & $9^{a}$ & 17-oct & $1^{\mathrm{a}}$ & $10^{\mathrm{a}}$ \\
\hline
\end{tabular}

a,b . Medidas seguidas de letras diferentes, en una misma columna, indican que hubo diferencias significativas a un nivel de significancia de 5\% en una prueba de comparación de Kruskal-Wallis (K-W). rama en los tres días evaluados $(\mathrm{p}=0.922)$, siendo una flor la mediana en las tres muestras, al igual que en las flores masculinas donde no existen diferencias entre los días evaluados $(\mathrm{p}=0.934)$, siendo 10 flores masculinas la mediana en los tres días evaluados.

El número de flores femeninas durante todo el periodo de floración fue mucho menor que el de las flores masculinas en los dos años de experimentación; resultados similares fueron obtenidos por Nepi et al. (1996), Vidal et al. (2006) en C. pepo y por Agbagwa et al. (2007) en C. moschata. Existe la necesidad de la intervención de un polinizador para garantizar el éxito reproductivo, pero esto requiere de la implementación de un estudio de ecología de la polinización para esta especie.

En el periodo de floración donde ambos tipos de flores estuvieron presentes, la tasa de flores masculinas sobre las femeninas fue constante en los tres días de evaluación. En las semanas de mayor producción de flores masculinas y femeninas, la tasa de producción fue de 10:1 a favor de las masculinas. En los periodos donde predominaba la floración masculina, la tasa de floración podía llegar hasta 20:1 a favor de las flores masculinas; resultados similares fueron mostrados por Vidal et al. (2006) en C. pepo.

Producción, viabilidad y diámetro del grano de polen de C. moschata.

El porcentaje de viabilidad fue evaluado el 23 de junio, 25 de julio y 27 de agosto del 2016. En la Figura 6 , se puede observar un decaimiento del porcentaje de viabilidad desde un $98 \%$ hasta un $70 \%$ desde la apertura floral (6:00 a.m. aproximadamente) hasta el cierre floral (1:30 p.m. aproximadamente). La última 


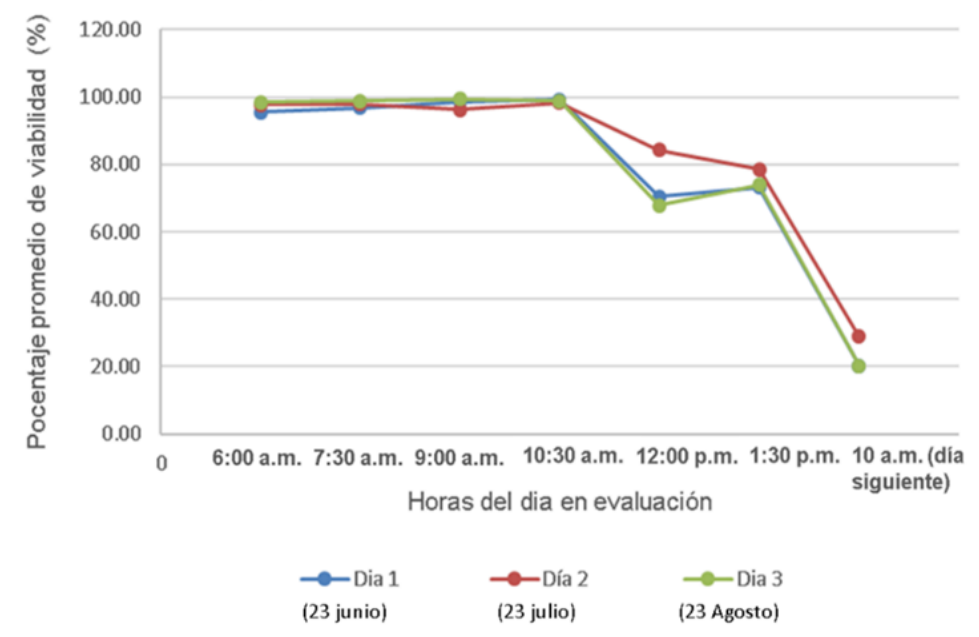

Figura 6. Porcentaje de viabilidad de los granos de polen de C. moschata evaluados en el año 2016.

evaluación de viabilidad se realizó 24 horas después de la extracción del polen de la flor, y en los tres días evaluados la viabilidad decayó hasta un $20 \%$.

Resultados similares fueron descritos por Agbagwa et al. (2007) en C. moschata y Nicodemo et al. (2007) en $C$. maxima; estos autores reportaron al inicio de antesis un porcentaje muy alto de viabilidad, por encima de $90 \%$, siguiendo un patrón de decaimiento hasta menos del $10 \%$ al día siguiente de la antesis floral.

Este patrón de decaimiento del porcentaje de viabilidad del polen es particular del género Cucurbita; la razón principal de este suceso fue estudiada por Gay et al. (1987), y está asociada a la deshidratación que sufre el grano de polen al encontrarse con el nuevo ambiente que se genera al abrirse la corola (antesis) y la susceptibilidad de este tipo de polen a la pérdida de agua.

\section{Producción de los granos de polen}

No se encontraron diferencias estadísticamente significativas entre el número de granos de polen producidos por flor en los tres días evaluados $(\mathrm{p}=0.394$ y $\mathrm{p}=0.179$ respectivamente) siendo el promedio para estos tres días evaluados en el 2015, de $27051+/-8$ 956 granos de polen por flor y en el 2016, de $31266+/-$ 11976 granos de polen por flor (Tabla 5).

Nicodemo et al. (2007) reportaron el mayor número de granos de polen entre las cucurbitáceas, llegando a contabilizar hasta $139667+/$ - 41091 granos de polen por flor. Cabe resaltar que la flor de esta especie tiene mayores dimensiones en tamaño que la de C. moschata y otras cucurbitáceas. En C. pepo, el número de granos de polen depende de la variedad en estudio, así se han reportado 16487 +/- 231 granos para la variedad Greyzinii y $43669+/-1382$ granos para la variedad Hauden. Para C. moschata han reportado 47715 granos de polen (Vidal et al. 2006).

\section{Diámetro de los granos de polen}

De la longitud promedio del diámetro de polen (en $\mathrm{mm}$ ) en las muestras tomadas en el 2015 (Tabla 6), se puede afirmar que si existen diferencias estadísticas entre el diámetro promedio de granos de polen por flor en los tres días evaluados $(\mathrm{p}=0.001)$. Para los días 2 y 3 , las medianas fueron $0.1467 \mathrm{~mm}$ y $0.1567 \mathrm{~mm}$ respectivamente y se separó como otro grupo de K-W al día 1 con una mediana de $0.1363 \mathrm{~mm}$. Se halló un promedio con los dos días que formaban un mismo grupo de K-W, obteniéndose $0.1449+/-0.027 \mathrm{~mm}$ como diámetro para las muestras evaluadas en el 2015.

De los granos de polen medidos durante el 2016 (Tabla 6), se puede afirmar que existen diferencias significativas entre el diámetro de granos de polen por flor en los tres días evaluados $(\mathrm{p}=0.000)$. Luego se hicieron comparaciones múltiples de Tukey, las cuales mostraron como un grupo a los días 1 y 2, donde las medias fueron $0.1755 \mathrm{~mm}$ y $0.1565 \mathrm{~mm}$ y separaron como otro grupo al día 1 con una media de $0.1483 \mathrm{~mm}$. Se halló un promedio con los dos días que formaban un

Tabla 5. Análisis comparativo del número de granos de polen por flor masculina evaluada en el año 2015 y 2016.

\begin{tabular}{|c|c|c|c|c|}
\hline Año de evaluación & & 2015 & & 2016 \\
\hline & 12-jul & $25042^{\mathrm{a}}$ & 27-jul & $29792^{\mathrm{a}}$ \\
\hline Fecha de evaluación & 15 -ago & $23500^{\mathrm{a}}$ & 20-sep & $26250^{\mathrm{a}}$ \\
\hline & 19-sep & $27292^{\mathrm{a}}$ & 15 -oct & $28500^{\mathrm{a}}$ \\
\hline $\begin{array}{l}\text { Intervalo de confianza } \\
\qquad(95 \%)\end{array}$ & & {$\left[\begin{array}{llll}25 & 125 & -27 & 833\end{array}\right]$} & & {$\left[\begin{array}{lllll}28 & 166 & - & 31 & 833\end{array}\right]$} \\
\hline
\end{tabular}


Tabla 6. Análisis comparativo del diámetro de los granos de polen en milímetros por flor masculina evaluada en el año 2015 y 2016.

\begin{tabular}{|c|c|c|c|c|}
\hline \multicolumn{2}{|c|}{ Año de evaluación } & \multicolumn{2}{|l|}{2015} & \multirow{2}{*}{$\begin{array}{r}2016 \\
0.1755^{\circ}\end{array}$} \\
\hline \multirow{3}{*}{$\begin{array}{l}\text { Fecha de } \\
\text { evaluación }\end{array}$} & 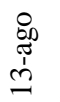 & $0.1363^{\mathrm{a}}$ & $\begin{array}{l}\text { 离 } \\
\text { 光 }\end{array}$ & \\
\hline & 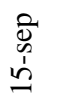 & $0.1467^{b}$ & $\begin{array}{l}0 \\
0 \\
0 \\
n \\
n\end{array}$ & $0.1565^{\mathrm{c}}$ \\
\hline & $\begin{array}{l}\overline{0} \\
0 \\
\stackrel{1}{1} \\
\text { N }\end{array}$ & $0.1567^{b}$ & $\begin{array}{l}\tilde{0} \\
0 \\
\grave{1} \\
\text { d }\end{array}$ & $0.1483^{\mathrm{d}}$ \\
\hline
\end{tabular}

Intervalo

de

confianza

$(95 \%)$ prueba, esta disminuyó hasta ser casi nula al séptimo día de evaluación.

Hasta el tercer día después de la antesis, se registró receptividad estigmática por Agbagwa et al. (2007); sin embargo, se debe indicar que la metodología seguida por estos autores consideró la formación del tubo polínico sobre el estigma.

En algunos casos, los resultados positivos de receptividad a partir del cuarto día después de antesis, se pueden deber a que con la prueba del peróxido de hidrógeno también resultan positivos estigmas constituidos por tejido deteriorado; por ello, Dafni \& Motter (1998) sugieren que esta prueba sea complementaria a otras pruebas más determinantes.

Por otro lado, tal como mencionan Nepi \& Pacini (1993) en C. pepo, en este estudio se comprobó también que el estigma es receptivo los días previos a la antesis.

\section{Producción de néctar}

De la evaluación que se realizó en el año 2015 (Tabla 8), se realizaron comparaciones de K-W $(\mathrm{p}=0.006)$, resultando como grupos de $\mathrm{K}-\mathrm{W}$ los días de evaluación 1 y 2 , donde las medianas fueron 8 y 8 ul de néctar por flor y separó como otro grupo al día 3 con una mediana de 9 ul. Se halló un promedio con los dos días que formaban un mismo grupo de $\mathrm{K}-\mathrm{W}$, así se tiene $8+/-0.131$ ul de néctar como volumen para las flores evaluadas en el 2015.

Por otro lado, en las muestras evaluadas a las 12:00 p.m. se realizó una prueba de comparaciones múltiples de Tukey (ANVA con $\mathrm{p}=0.002$ ), las cuales mostraron como un grupo a los días 1 y 3 , donde las medias fueron 44.47 y 47.87 ul de néctar por flor y separó como otro grupo al día 2 con una media de 47.87 ul. Se halló también un promedio con los dos días que formaban un mismo grupo de Tukey, así se tiene 44.11+/- 0.895 ul de néctar como volumen para las flores femeninas evaluadas a las 12 p.m. en el 2015.

En las muestras de las flores masculinas evaluadas a las 6:00 a.m, se realizó una prueba de $\mathrm{K}-\mathrm{W}(\mathrm{p}=0.124)$. Se halló un promedio con los tres días evaluados; así, se tiene $2.83+/-0.119$ ul de néctar como volumen para las flores masculinas evaluadas a las 6 a.m. en el 2015.

De igual manera, en las muestras evaluadas a las 12:00 p.m., se realizó una prueba de comparaciones múltiples de Tukey (ANVA de $\mathrm{p}=0.000$ ), la cual presentó como un grupo a los días de evaluación 1 y 3 , donde las medias fueron 16.46 y 15.10 ul de néctar por flor y separó como otro grupo al día 2 de evaluación con una media de 22.43 ul. Se halló también un

Tabla 7. Receptividad del estigma en 30 flores femeninas de $C$. moschata durante 7 días consecutivos en los años 2015 y 2016.

\begin{tabular}{cccccccc}
\hline Año de & \multicolumn{8}{c}{ Días evaluados } \\
evaluación & Día & Día & Día & Día & Día & Día & Día \\
& 1 & 2 & 3 & 4 & 5 & 6 & 7 \\
\hline 2015 & 4 & 4 & 4 & 3 & 2 & 1 & 0 \\
2016 & 4 & 4 & 3 & 3 & 2 & 1 & 1 \\
\hline
\end{tabular}

1-4, intensidad del burbujeo (1, menos intenso; 4, más intenso). 
promedio con los dos días que formaban un mismo grupo de Tukey, así se tiene 18.00 +/- 0.626 ul como volumen de néctar para las flores masculinas evaluadas a las 12 p.m. en el 2015.

De la evaluación que se realizó en el año 2016 (Tabla 9), el análisis de K-W (p=0.002) mostró diferencias significativas. Por ello, se realizó una prueba de comparaciones múltiples, la cual mostró como un grupo de $\mathrm{K}-\mathrm{W}$ a los días 1 y 2 , donde las medianas fueron 9 y 10 ul de néctar por flor y separó como otro grupo al día 3 de evaluación con una mediana de 12 ul. Se halló un promedio con los dos días que formaban un mismo grupo de $\mathrm{K}-\mathrm{W}$, así se tiene 8 +/- 0.131 ul de néctar como volumen para las flores evaluadas en el 2016

Por otro lado, después del análisis de K-W $(\mathrm{p}=0.002)$ en las muestras evaluadas a las 12:00 p.m., se realizó una prueba de comparaciones múltiples la cual indica que no existen agrupamientos, es decir que todos los días evaluados son diferentes entre sí, es por ello, que no fue posible hallar un promedio para los tres días evaluados.

En las muestras de las flores masculinas evaluadas a las 6:00 a.m., el análisis de $\mathrm{K}-\mathrm{W}(\mathrm{p}=0.803)$ permitió hallar un promedio con los tres días evaluados, así se tiene $3.61+/-0.183$ ul como volumen para las flores masculinas evaluadas a las 6 a.m. en el 2016.

Por otro lado, en las muestras evaluadas a las 12:00 p.m., se realizó una prueba de comparaciones múltiples de Tukey (ANVA con $\mathrm{p}=0.000$ ), la cual indicó que hay

Tabla 8. Producción de néctar (ul) de las flores masculinas y femeninas en el 2015.

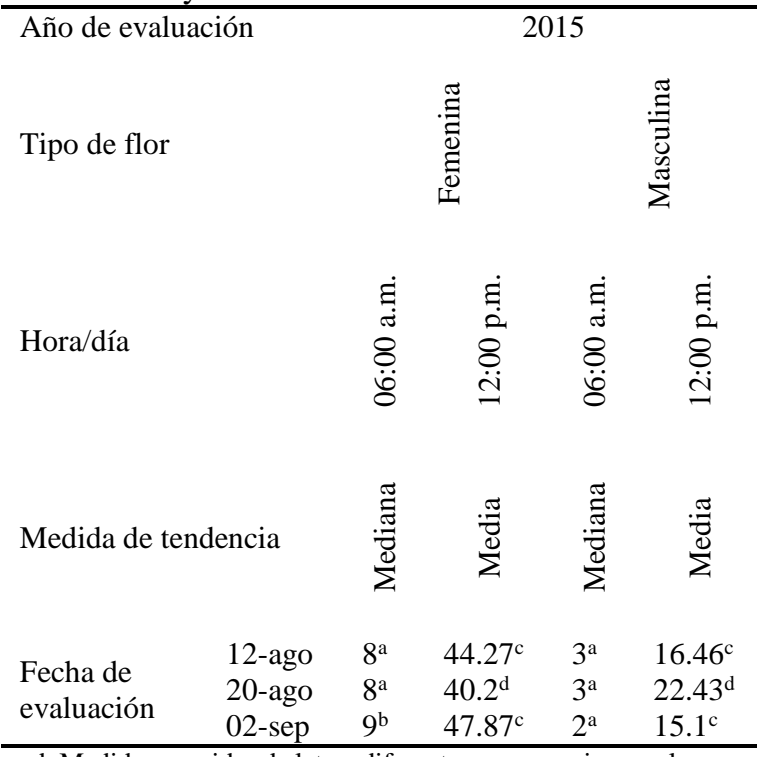

a,b Medidas seguidas de letras diferentes, en una misma columna, indican que hubo diferencias significativas a un nivel de significancia de $5 \%$ en una prueba de comparación de KruskalWallis $(\mathrm{K}-\mathrm{W})$.

$\mathrm{c}, \mathrm{d}$ Medidas seguidas de letras diferentes, en una misma columna, indican que hubo diferencias significativas a un nivel de significancia de $5 \%$ en una prueba de comparación de Tukey.
Tabla 9. Producción de néctar (ul) de las flores femeninas y masculinas en el 2016.

\begin{tabular}{|c|c|c|c|c|c|}
\hline \multicolumn{2}{|c|}{ Año de evaluación } & \multicolumn{4}{|c|}{2016} \\
\hline \multicolumn{2}{|l|}{ Tipo de flor } & \multicolumn{2}{|c|}{ 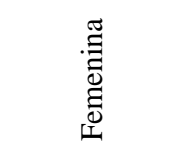 } & \multicolumn{2}{|r|}{ 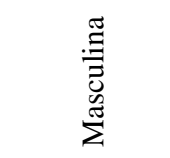 } \\
\hline Hora/día & & $\begin{array}{l}\dot{\Xi} \\
\dot{\theta} \\
8 \\
\ddot{8}\end{array}$ & 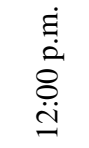 & $\begin{array}{l}\dot{\Xi} \\
\dot{\delta} \\
\stackrel{8}{8} \\
\dot{8}\end{array}$ & $\begin{array}{l}\dot{g} \\
\dot{2} \\
\stackrel{8}{8} \\
\dot{d}\end{array}$ \\
\hline \multicolumn{2}{|c|}{ Medida de tendencia } & 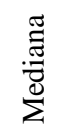 & 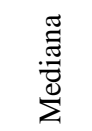 & 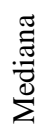 & $\frac{\pi}{\tilde{g}}$ \\
\hline \multirow{3}{*}{$\begin{array}{l}\text { Fecha de } \\
\text { evaluación }\end{array}$} & 07-sep & $9^{\mathrm{a}}$ & $38.5^{\mathrm{a}}$ & $3^{\mathrm{a}}$ & $20.27^{e}$ \\
\hline & 13-sep & $10^{\mathrm{a}}$ & $39^{\mathrm{b}}$ & $4^{\mathrm{a}}$ & $25.5^{\mathrm{f}}$ \\
\hline & 27-sep & $12^{\mathrm{b}}$ & $42^{c}$ & $3^{\mathrm{a}}$ & $30.73^{\mathrm{g}}$ \\
\hline
\end{tabular}

a, b y c Medidas seguidas de letras diferentes, en una misma columna, indican que hubo diferencias significativas a un nivel de significancia de $5 \%$ en una prueba de comparación de KruskalWallis (K-W).

e, f y g Medidas seguidas de letras diferentes, en una misma columna, indican que hubo diferencias significativas a un nivel de significancia de 5\% en una prueba de comparación de Tukey.

tres grupos diferentes, por lo tanto, los tres días evaluados poseen diferentes volúmenes en promedio.

De todas las mediciones realizadas, las flores femeninas han producido un mayor volumen de néctar que las flores masculinas en ambas horas del día en evaluación. Esta misma información ha sido obtenida en $C$. maxima subsp. andreana (Ashworth \& Galetto, 1999), en C. maxima cultivar Exposisao (Nicodemo et al., 2007) y en C. pepo (Vidal et al., 2006).

Con respecto al volumen de néctar obtenido en el presente estudio, éste difiere de otros estudios realizados en cucurbitáceas, y dentro de éstos también existen diferencias. Este hecho podría estar relacionado con tamaño del nectario, ya que las flores femeninas poseen un tamaño de nectario más grande que las masculinas, tal como se observó en los estudios de morfología floral realizados en esta investigación.

Factores que se pueden considerar son la temperatura y radiación solar a la hora y en el día de la extracción del néctar, los que han sido diferentes en todas las repeticiones y experimentos realizados por otros autores; sin embargo, a pesar de estas diferencias, se ha observado también que el incremento en la producción de néctar coincide con el incremento de la temperatura desde la hora de apertura hasta el cierre floral; este suceso también fue observado por Vidal et al. (2006).

Por último, el volumen de néctar producido a lo largo de todo el periodo de floración no es constante y esto se puede deber a factores climáticos como humedad relativa, temperatura y radiación solar, los 
Tabla 10. Sistemas de polinización en Cucurbita moschata.

\begin{tabular}{|c|c|c|c|c|}
\hline Grupo & 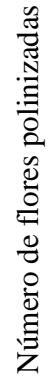 & 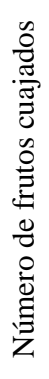 & 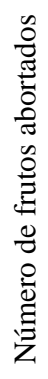 & 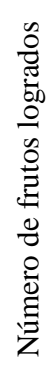 \\
\hline I) Autogamia-Geitonogamia & 10 & 9 & 5 & 4 \\
\hline II) Apomixis & $0 *$ & 3 & 0 & 3 \\
\hline III) Alogamia-Xenogamia & 10 & 9 & 4 & 5 \\
\hline IV) Polinización abierta & 10 & 10 & 4 & 6 \\
\hline
\end{tabular}

*Diez flores femeninas fueron embolsadas con la finalidad que no fueran polinizadas.

cuales afectan la producción de néctar (Nepi \& Pacini, 1993; Nepi et al., 1996; Vidal et al., 2006).

Biología reproductiva.

\section{Sistemas de polinización y reproductivo.}

En la Tabla 10 se muestra el número de frutos cuajados, abortados y logrados. A partir de esta información y utilizando las pruebas de polinización propuestas por por Shivanna \& Tandon (2014), se puede decir que $C$. moschata presenta diferentes tipos de polinización como la geitonogamia, polinización cruzada y polinización abierta por medio de insectos. Al presentar la formación de frutos en todos los tratamientos de polinización se puede decir que $C$. moschata es una planta autocompatible por medio de geitonogamia, alógama-xenógama y apomíctica. En todos los grupos de evaluación se produjeron frutos de morfología normal (Figura 7) y con presencia de semillas.

El sistema de reproducción de una especie determina la forma en que las semillas son producidas y el grado de dependencia de las plantas de los polinizadores para el cuajado de fruto (Pang et al., 2012). El mayor porcentaje de frutos producidos fue en el grupo de polinización abierta con $60 \%$ de frutos formados. De los frutos cuajados, varios de ellos no continuaron su crecimiento y desarrollo después del cuajado debido al ataque de hongos que se desarrollan en ambientes con alta humedad relativa (H.R.), ambiente característico del departamento de Lima (H.R. 95\%) a diferencia de la humedad presente en la zona de procedencia del cultivo de $C$. moschata, es decir la zona norte del Perú, que presenta una H.R. de $86 \%$.

Agbagwa et al. (2007) reportaron para C. moschata un $70 \%$ de frutos formados; estos resultados son similares a los obtenidos en este trabajo; sin embargo, no mencionan si el $30 \%$ restante que no se formó, fue debido al aborto o a la falta de polinización.
Robinson \& Reiners (1999) en un estudio de partenocarpia en $C$. pepo, reportaron la formación de frutos partenocárpicos (aquellos que sin polinización forman frutos sin semillas). Durante dos años de evaluación obtuvieron la formación de este tipo de frutos y asociaron este suceso a las bajas temperaturas presentes en el periodo de floración. Además, observaron que los frutos partenocárpicos y los procedentes de otros tipos de polinización eran iguales morfológicamente.

En el presente estudio no se formaron frutos partenocárpicos, pero si se formaron frutos apomícticos por medio de agamospermia (aquellos frutos con semillas que se forman sin polinización). De las 10 flores femeninas evaluadas, el 33.3\% formaron frutos y al igual que Robinson \& Reiners (1999), la formación de estos frutos coincidió con la presencia de bajas temperaturas durante el mes de agosto. Asimismo, se observó que fueron más pequeños y con una menor cantidad de semillas.

Considerando el número de óvulos, se obtuvo en promedio $60.33+/-3.74$ a partir de 18 frutos. A partir de esta información y el número de granos de polen se halló la tasa polen: óvulo, siendo ésta 518:1. Este valor reitera que $C$. moschata presenta un sistema reproductivo basado en la xenogamia facultativa,

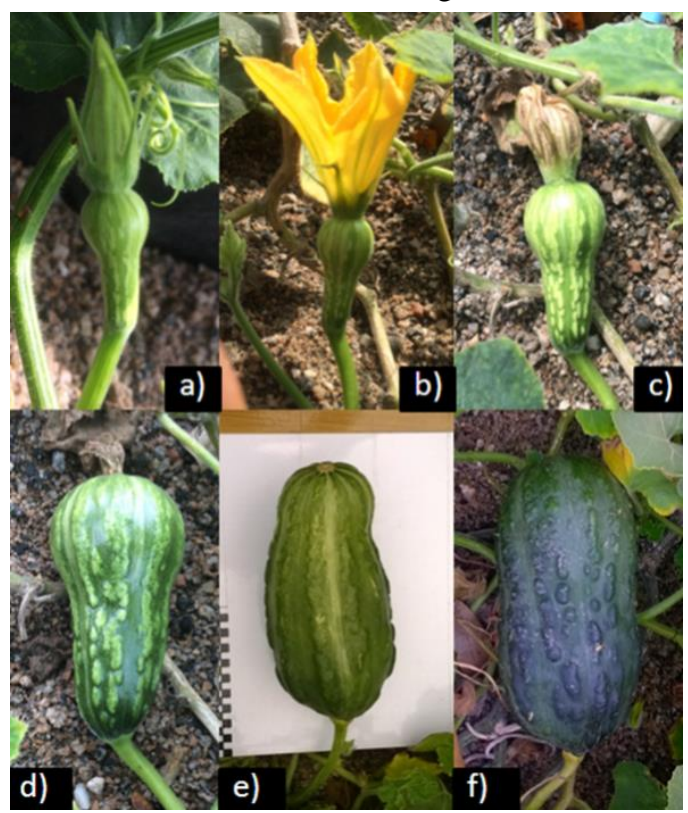

a) Flor femenina un día previo a la antesis, b) flor femenina polinizada en el día de antesis, c) flor femenina al día siguiente de ser polinizada, d) flor femenina una semana después de la polinización, nótese la marchitez de la corola, e) fruto de loche en pleno desarrollo con tres semanas después de la polinización y f) fruto de loche maduro, nótese el color verde oscuro del peridermis.

Figura 7. Desarrollo del fruto de Loche (Cucurbita moschata). 
Tabla 11. Visitantes florales de $C$. moschata en tres campos agrícolas ubicados en Chiclayo, Lambayeque.

\begin{tabular}{lllllc}
\hline \multicolumn{1}{c}{ Orden } & \multicolumn{1}{c}{ Familia } & Género & $\begin{array}{c}\text { Regularidad } \\
\text { en campo }\end{array}$ & $\begin{array}{c}\text { Duración } \\
\text { de visita }\end{array}$ & $\begin{array}{c}\text { Número } \\
\text { individuos } \\
\text { por flor }\end{array}$ \\
\hline Coleoptera & Chrysomelidae & Diabrotica & Raro & $>15 \mathrm{~min}$ & 1 \\
Diptera & Drosophilidae & & Mayor & $>30 \mathrm{~min}$ & $>10$ \\
Hemiptera & Reduviidae & & Raro & $<10 \mathrm{~min}$ & $<2$ \\
Lepidoptera & Noctuidae & & Raro & $<5 \mathrm{~min}$ & 1 \\
Hymenoptera & Vespidae & & Regular & $<10 \mathrm{~min}$ & 1 \\
& Apidae & Apis & Mayor & $<10 \mathrm{~min}$ & $<2$ \\
& Hakictidae & & Raro & $<10 \mathrm{~min}$ & 1 \\
& Andrenidae & & Regular & $<10 \mathrm{~min}$ & 1 \\
\hline
\end{tabular}

donde si no ocurre una polinización cruzada ocurriría autopolinización del tipo geitonógama (Lyon, 1992). Resultados similares fueron obtenidos por Nepi \& Pacini (1993) en C. pepo con una tasa polen: óvulo de 317:1.

\section{Polinización y visitantes florales}

Se visitaron tres campos de cultivo en la zona de Pomac III en el distrito de Pítipo en Lambayeque, los que se encontraron en estado de floración y antesis durante los tres días de visita. Estos campos agrícolas se llevaban un mes de diferencia desde su plantación.

De los resultados obtenidos y resumidos en la Tabla 11 se indica que el orden Hymenoptera tiene el mayor número de familias con afinidad por las flores del "Loche". De ellas, las familias Vespidae y Apidae son las de mayor regularidad y las que han sido encontradas en los campos de este cultivo. Las recompensas florales influyen directamente en la conducta del polinizador y como consecuencia afecta el éxito reproductivo de las plantas, ya sea incrementando las visitas del polinizador como lo ocurrido con el orden Hymenoptera o aumentando la probabilidad de éxito de la polinización (Pang et al., 2012), permaneciendo un periodo de tiempo más largo dentro de la flor como en el caso del orden Diptera, cuyas visitas a las flores de C. moschata duraron hasta 30 minutos al igual que el orden Hymenoptera.

Los órdenes con poca frecuencia en el campo fueron Hemiptera y Lepidoptera con solo un ejemplar colectado por cada uno. Todos los órdenes presentados en la Tabla 11 también han sido registrados por Ashworth \& Galetto (2001) en C. maxima.

Como visitante floral más frecuente se tiene al género Apis, siendo éste el que siempre se encuentra en todas las cucurbitáceas, tal como lo indican Agbagwa et al. (2007) y Nicodemo et al. (2009). El polen que se pega al cuerpo de las Apis sp. durante sus visitas a las flores de $C$. moschata que luego sirve para polinizar otras flores, y como alimento para estos polinizadores, ya que es esencial para el crecimiento de los mismos (Vidal et al., 2010).

Las flores femeninas son las que reciben la mayor cantidad de visitas florales, esto puede estar relacionado al volumen de néctar que es mayor que en las flores masculinas; esta observación ha sido registrada también por Agbagwa et al. (2007) para $C$. moschata y por Nepi et al. (1996) en C. pepo. Además, el tamaño de la corola de las flores femeninas posibilita un acceso más rápido y simple del polinizador hacia el nectario y una estancia más prolongada de éste por el mayor volumen de néctar secretado, ya que, les tomaría más tiempo extraerlo; sin embargo, anatómicamente, las flores masculinas proporcionan una mayor facilidad para la obtención del néctar por parte de los polinizadores (Nepi et al., 1996). Así mismo, no solo de estos medios se valen las flores masculinas para atraer a los polinizadores sino también de la confusión que puede causar la apariencia externa tan similar de ambos tipos de flores en $C$. moschata.

\section{Conclusiones.}

El Loche de Lambayeque (Cucurbita moschata Duchesne) es una planta monoica con flores unisexuales solitarias y actinomorfas, de perianto pentámero. En esta especie las flores masculinas inician la fenofase de floración antes que las femeninas.

En lo que respecta a la antesis, las flores femeninas inician horas antes este proceso; sin embargo, ambos tipos de flores coinciden en la hora de cierre floral. La producción de flores es dependiente de la temperatura, hacia un mayor número de flores masculinas con respecto a las femeninas.

El polen de Cucurbita moschata tiene una viabilidad del $98 \%$ desde la antesis y decae hasta un $20 \%$ al día siguiente.

La receptividad del estigma es intensa hasta el tercer día después de la antesis, pero disminuye hasta ser casi nula al séptimo día.

Cucurbita moschata presenta diferentes tipos de polinización como la geitonogamia, polinización cruzada y polinización abierta por medio de insectos. Ademas, es una planta autocompatible por medio de geitonogamia, alógama-xenógama y presenta apomixis del tipo agamospermia.

El Orden Hymenoptera tiene el mayor número de familias con afinidad por las flores del "Loche". Las familias Vespidae y Apidae son las de mayor 
regularidad en visitas, siendo Drosophila sp. la de mayor duración en estancia.

\section{Agradecimientos.}

Al Biólogo Jorge Lujan Leiva por la identificación de los polinizadores y visitantes florales.

Al Fondo Nacional de Desarrollo Científico y Tecnológico por el financiamiento del proyecto "Biología reproductiva sexual y expresión genómica durante el desarrollo floral del Loche (Cucurbita moschata Duchesne)". Convenio $\mathrm{N}^{\circ}$ 106-2014FONDECYT-DE, en cuyo marco se desarrolló esta investigación.

\section{Literatura citada.}

Agbagwa O., Ndukwu B. \& Mensah S. 2007. Floral biology, breeding system, and pollination ecology of Cucurbita moschata (Duch. Ex Lam) Duch. Ex. Poir. Varieties (Cucurbitaceae) from parts of the Niger Delta, Nigeria. Turkish Journal of Botany 31:451-458.

Ashworth L. \& Galetto L. 1999. Morfo-anatomía cuantitativa de las flores pistiladas y estaminadas de Cucurbita maxima subsp. andreana (Cucurbitaceae). Darwiniana 37(3-4):187-198.

Ashworth L. \& Galetto L. 2001. Pollinators and reproductive success of the wild cucurbit Cucurbita maxima ssp. andreana (Cucurbitaceae). Plant biology 3:398-404.

Bustamante F. \& Ugás R. 2006. Loche: a unique precolumbian squash locally grown in north coastal Peru. En: Proceedings of Cucurbitaceae. North Carolina, US. Universal Press. 333-340 p.

Corredor J.P. \& García J. 2011. Fenología reproductiva, biología floral y visitantes florales en los cultivares de mango (Mangifera indica L.) Hilacha y Tommy Atkins en el valle del alto Magdalena (Colombia). Corpoica, ciencia y tecnología agropecuaria. 12(1):21-32.

Crase B. 2011. Cucurbitaceae in: Short P.S. \& Cowie I.D. Floral of the Darwin Region. (Northern Territory Herbarium, Department of Natural Resources, Environment, the Arts and Sport) (1)1-5 pp.

Cruden R. W. 1977. Pollen-ovule ratios: a conservative indicator of breeding systems in flowering plants. Evolution 31, 32-46. doi: 10.1111/j.15585646.1977.tb00979.x

Dafni A. \& Motte M. 1998. A rapid and simple procedure to determine stigma receptivity. Sex Plant Reproduction 11:177-180.

Dafni A. 1992. A Pollination ecology: a practical approach. New York: IRL, $250 \mathrm{p}$.

Delgado G., Rojas C., Sencie A. \& Vásquez L. 2014 Caracterización de frutos y semillas de algunas cucurbitáceas en el norte del Perú. Revista Fitotecnica Mexicana. 37(1): 7-20.

Gay G., Kerhoas C. \& Dumas C. 1987. Quality of stresssensitive Cucurbita pepo L. pollen. Planta 171:82-87.

Hayward H. 1953. Estructuras de las plantas útiles. Acme, Buenos Airees. 575-614 p.
INTA. 2013. Manual de cultivo del zapallo anquito (Cucurbita moschata Duch.) (En línea). Mendoza, AR. INTA. Consultado el 24 de abr. 2015. Disponible en http://inta.gob.ar/documentos/manual-del-cultivo-delzapello-anquito-cucurbita-moschataduch/at_multi_download/file/Manual\%20de\%20Zapallo .pdf.

Lira R. \& Rodríguez I. 1999. Flora del Valle de TehuacánCuicatlán: Cucurbitaceae A.L. Juss. México. D. R. Universidad Nacional Autónoma de México. Fascículo 22.

López Bonilla C., Espejo R. \& Mansilla R. 2014. El Loche (Cucurbita moschata Duschesne Ex. Lam), su historia, cultivo, características agroclimáticas, genéticas y composición del fruto. Lima, PE. Fondo editorial UNALM.

Lyon D.L. 1992. Bee pollination of facultatively xenogamous Sanguinaria canadensis L. Bulletin of the Torrey Botanical Club. 119(4): 368-375.

Lyra D., Sampio L., Pereira D., Silva A. \& Amaral C. 2011. Pollen viability and germination on Jatropha ribifolia and Jatropha mollisisina (Euphorbiaceae): Species with potential for biofuel production. African Journal of Biotechnology 10(3): 368-374.

Mansilla R., López C., Flores M. \& Espejo R. 2010. Estudios de la biología reproductiva en cinco accesiones de Smallanthus sonchifolius (Poepp. \& Endl.) Robinson. Ecología aplicada 9(2):167-175.

Maynard L. 2007. Cucurbit Crop Growth and Development. University of Purdue Conference Proceedings, Indiana, United States of America. Disponible en Linea: https://www.agry.purdue.edu/CCA/2007/2007/Proceedi ngs/Liz\%20MaynardCCA\%20proceedings\%201_KLS.pdf.

McInnis S.M., Emery D.C., Porter R., Desikan R., Hancock J.T. \& Hiscock S.J. 2006. The role of stigma peroxidases in flowering plants insights from further characterization of a stigma-specific peroxidases (SSP) from Senecio squalidus (Asteraceae). J. Exp.Bot. 8, 1835-1846.

Meier U. 2001. Growth stages of mono-and dicotyledonous plants. 2 edition. Federal Biological Research Centre for Agriculture and forestry.

Nepi M. \& Pacini E. 1993. Pollination, pollen viability and pistil receptivity in Cucurbita pepo. Annals of Botany 72: 527-536.

Nepi M., Pacini E. \& Willemse T. 1996. Nectary biology of Cucurbita pepo: ecophysiological aspects. Acta Bot. Neerl. 45(1):41-45.

Nicodemo D., Nogueira R., Braga E. \& De Jong D. 2007. Biologia floral em moranga (Cucurbita maxima Duch. var. "Exposição"). Acta Sci. Agron. 29:611-616.

Nicodemo D., Nogueira R., Braga E. \& De Jong D. 2009. Honey bee as an effective pollinating agent of pumpkin. Sci. Agric. 66:476-480.

Pang S., Pan K., Wang Y., Li W., Zhang L. \& Chen Q. 2012. Floral morphology and reproductive biology of Dendrobium jiajiangense (Orchidaceae) in Mt. Fotang, southwestern China. Flora 207: 469-474.

Rafael J.A., Melo G., De Carvalho C., Casari S. \& Constantino R. 2012. Insectos do Brasil: diversidad y taxonomía. Riberao, BR. Holos.

Robinson R.W. \& Reiners S. 1999. Parthenocarpy in summer squash. HortScience 34: 715-717 
Sánchez Ocharan C. 2015. Estudio de la biología floral y reproductiva en Caesalpinia spinosa (Feuillée ex Molina) Kuntze "Tara". Tesis. Lima, PE. UNALM.

Shivanna K.R. \& Tandon R. 2014. Reproductive Ecology of Flowering Plants: A Manual. Springer. New Delhi, IN.

Ugás R. 2014. 40 viejas y nuevas verduras para diversificar tu alimentación y nutrirte mejor. Lima, PE. Gamma gráfica.

Vidal M., De Jong D., Wien H. \& Morse R. 2006. Nectar and pollen production in pumpkin (Cucurbita pepo L.). Revista Brasil. Bot. 29(2):276-273.
Vidal M., De Jong D., Wien H. \& Morse R. 2010. Pollination and fruit set in pumpkin (Cucurbita pepo). Revista Brasil. Bot. 33(1):107-113.

Wessel-Beaver L., Sud J. \& Cuevas H. 2004. Morphological traits of possible use as species markers in Cucurbita moschata and $C$. argryosperma. Cucurbit Genetics Cooperative Report 27:54-56.

Whitaker T. \& Davis G. 1962. Cucurbits, botany, cultivation and utilization. Leonard Hill, New York.

${ }^{1}$ Instituto de Biotecnología. Universidad Nacional Agraria La Molina. Av. La Molina s/n. Lima-Perú. *Autor de correspondencia isamar.bazo@gmail.com

2 Instituto de Biotecnología. Universidad Nacional Agraria La Molina. Av. La Molina s/n. Lima-Perú. respejo@lamolina.edu.pe

3 Instituto de Biotecnología. Universidad Nacional Agraria La Molina. Av. La Molina s/n. Lima-Perú. cepalomino@gamil.com

${ }^{4}$ Herbario Mol (a. "Augusto Weberbauer"). Departamento de Biología. Universidad Nacional Agraria La Molina. Av. La Molina s/n. Lima-Perú. mflores@lamolina.edu.pe

${ }^{5}$ Centro de Investigación de Hidroponía y Nutrición Mineral. Universidad Nacional Agraria La Molina. Av. La Molina s/n. Lima-Perú. milichang@lamolina.edu.pe

6 Instituto de Biotecnología. Universidad Nacional Agraria La Molina. Av. La Molina s/n. Lima-Perú. cflb@lamolina.edu.pe

7 Instituto de Biotecnología. Universidad Nacional Agraria La Molina. Av. La Molina s/n. Lima-Perú. rmansilla@lamolina.edu.pe 